\title{
EDITORIALS
}

693 The European Respiratory Society evaluates its 2013-2018 strategic plan implementation

Giovanni Battista Migliori, Elisabeth Bel, Guy Joos, Mark Elliott, Gernot Rohde, Stephen T. Holgate, Christina Gratziou, Dan Smyth, Mina Gaga, Carlos Robalo Cordeiro, Otto C. Burghuber, Guy Brusselle, Fernando Martin-Burrieza, Werner Bill,

Betty Sax and Jørgen Vestbo

699 Accuracy of diagnostic testing in primary ciliary dyskinesia: are we there yet? Eric G. Haarman and Miriam Schmidts

702 Clinical significance and management of right heart thrombi: more questions than answers David Jiménez and Roger D. Yusen

704 Diagnostics for latent TB infection: incremental, not transformative progress Madhukar Pai and Giovanni Sotgiu

707 Specific antigen(s) in sarcoidosis: a link to autoimmunity? Gernot Zissel and Joachim Müller-Quernheim

710 Catch-up alveolar development into adulthood: also in those born prematurely? Peter J.F.M. Merkus

714 A model for active and healthy ageing with a rare genetic disease: cystic fibrosis

Raphael Chiron, Davide Caimmi, Arunas Valiulis, Isabelle Durieu, Patrick Tejedor, Yam Le Cam, Mathieu Boudes, Oliver Jonquet, Timo Strandberg, Jean-Pierre Michel, Esteban de Manuel Keenoy, Pascal Demoly, Jacques Mercier, Radolphe Bourret and Jean Bousquet on behalf of MACVIA-LR European Innovation Partnership on Active and Healthy Ageing Reference Site

720 Histological grading in lung cancer: one system for all or separate systems for each histological type? William D. Travis, Elisabeth Brambilla and Kim R. Geisinger

\section{TASK FORCE REPORT}

ERS statement

724 Towards the standardisation of lung sound nomenclature

Hans Pasterkamp, Paul L.P. Brand, Mark Everard, Luis Garcia-Marcos, Hasse Melbye and Kostas N. Priftis

\section{ORIGINAL ARTICLES}

Epidemiology

Commuting mode and pulmonary function in Shanghai, China

Adam W. Gaffney, Jing-qing Hang, Mi-Sun Lee, Li Su, Feng-ying Zhang and David C. Christiani

COPD and lung function

ung function, forced expiratory volume in $1 \mathrm{~s}$ decline and COPD hospitalisations over 44 years of follow-up

Suneela Zaigham, Per Wollmer and Gunnar Engström

Asthma

751 Fractional exhaled nitric oxide for the management of asthma in adults: a systematic review

Munira Essat, Sue Harnan, Tim Gomersall, Paul Tappenden, Ruth Wong, lan Pavord, Rod Lawson and Mark L. Everard

769 Activin-A is overexpressed in severe asthma and is implicated in angiogenic processes

Konstantinos Samitas, Nikolaos Poulos, Maria Semitekolou, Ioannis Morianos, Sofia Tousa, Erasmia Economidou,

Douglas S. Robinson, Harsha H. Kariyawasam, Eleftherios Zervas, Christopher J. Corrigan, Sun Ying, Georgina Xanthou and

Mina Gaga

Inhibition of Pim1 kinase, new therapeutic approach in virus-induced asthma exacerbations

Maaike de Vries, Nicole Bedke, Natalie P. Smithers, Matthew Loxham, Peter H. Howarth, Martijn C. Nawijn and Donna E. Davies

792 Airway dysbiosis: Haemophilus influenzae and Tropheryma in poorly controlled asthma

Jodie L. Simpson, Joshua Daly, Katherine J. Baines, lan A. Yang, John W. Upham, Paul N. Reynolds, Sandra Hodge, Alan L. James, Philip Hugenholtz, Dana Willner and Peter G. Gibson

Trends and predictors of asthma costs: results from a 10-year longitudinal study

Ngiap Chuan Tan, Hai V. Nguyen, Weng Kit Lye, Usha Sankari and Nivedita V. Nadkarni

Paediatric pulmonology

Prenatal exposure to antibiotics and wheezing in infancy: a birth cohort study

release

Maja Popovic, Franca Rusconi, Daniela Zugna, Claudia Galassi, Franco Merletti, Enrica Migliore, Morena Trevisan,

Tiziana Nannelli, Luigi Gagliardi and Lorenzo Richiardi 
Cystic fibrosis and primary ciliary dyskinesia

829

Changes in airway inflammation during pulmonary exacerbations in patients with cystic fibrosis and primary ciliary dyskinesia Felix Ratjen, Valerie Waters, Michelle Klingel, Nancy McDonald, Sharon Dell, Timothy Ronan Leahy, Yvonne Yau and Hartmut Grasemann

Primary ciliary dyskinesia

\section{CME article 837 Accuracy of diagnostic testing in primary ciliary dyskinesia}

Claire L. Jackson, Laura Behan, Samuel A. Collins, Patricia M. Goggin, Elizabeth C. Adam, Janice L. Coles, Hazel J. Evans, Amanda Harris, Peter Lackie, Samantha Packham, Anton Page, James Thompson, Woolf T. Walker, Claudia Kuehni and Jane S. Lucas

Press $849 \quad$ An international registry for primary ciliary dyskinesia release Claudius Werner, Martin Lablans, Maximilian Ataian, Johanna Raidt, Julia Wallmeier, Jörg Große-Onnebrink, Claudia E. Kuehni, Eric G. Haarman, Margaret W. Leigh, Alexandra L. Quittner, Jane S. Lucas, Claire Hogg, Michal Witt, Kostas N. Priftis, Panayiotis Yiallouros, Kim G. Nielsen, Francesca Santamaria, Frank Ückert and Heymut Omran

Sleep

860 Impact of sleep disturbances on kidney function decline in the elderly

Isabelle Jaussent, Jean-Paul Cristol, Benedicte Stengel, Marie-Laure Ancelin, Anne-Marie Dupuy, Alain Besset, Catherine Helmer, Karen Ritchie, Claudine Berr and Yves Dauvilliers

Pulmonary vascular disease

Outcome of patients with right heart thrombi: the Right Heart Thrombi European Registry

Marcin Koć, Maciej Kostrubiec, Waldemar Elikowski, Nicolas Meneveau, Mareike Lankeit, Stefano Grifoni, Agnieszka Kuch-Wocial, Antoniu Petris, Beata Zaborska, Branislav S. Stefanović, Thomas Hugues, Adam Torbicki, Stavros Konstantinides and Piotr Pruszczyk for the RiHTER Investigators

$876 \quad$ Nestin-expressing vascular wall cells drive development of pulmonary hypertension

Farhan Saboor, Ansgar N. Reckmann, Claudia U.M. Tomczyk, Dorothea M. Peters, Norbert Weissmann, Andre Kaschtanow, Ralph T. Schermuly, Tatyana V. Michurina, Grigori Enikolopov, Dieter Müller, Andrea Mietens and Ralf Middendorff

Interstitial lung diseases

889 Recombinant human pentraxin-2 therapy in patients with idiopathic pulmonary fibrosis: safety, pharmacokinetics and exploratory efficacy

Bernt van den Blink, Marlous R. Dillingh, Leo C. Ginns, Lake D. Morrison, Matthijs Moerland, Marlies Wijsenbeek, Elizabeth G. Trehu, Brian J. Bartholmai and Jacobus Burggraaf

898 T-cell receptor-HLA-DRB1 associations suggest specific antigens in pulmonary sarcoidosis

Johan Grunewald, Ylva Kaiser, Mahyar Ostadkarampour, Natalia V. Rivera, Francesco Vezzi, Britta Lötstedt, Remi-André Olsen, Lina Sylwan, Sverker Lundin, Max Käller, Tatiana Sandalova, Kerstin M. Ahlgren, Jan Wahlström, Adnane Achour, Marcus Ronninger and Anders Eklund

$910 \quad$ NLRP3 inflammasome expression in idiopathic pulmonary fibrosis and rheumatoid lung Ismini Lasithiotaki, loannis Giannarakis, Eliza Tsitoura, Katerina D. Samara, George A. Margaritopoulos, Christiana Choulaki, Eirini Vasarmidi, Nikolaos Tzanakis, Argyro Voloudaki, Prodromos Sidiropoulos, Nikolaos M. Siafakas and Katerina M. Antoniou

Tuberculosis

919 Sensitivity of C-Tb: a novel RD-1-specific skin test for the diagnosis of tuberculosis infection Soren T. Hoff, Jonathan G. Peter, Grant Theron, Mellissa Pascoe, Pernille N. Tingskov, Henrik Aggerbeck, Daniel Kolbus, Morten Ruhwald, Peter Andersen and Keertan Dheda

929 Light-emitting diode fluorescence microscopy for tuberculosis diagnosis: a meta-analysis Eva W. Chang, Anne-Laure Page and Maryline Bonnet

Lung cancer

938 Proposal of a prognostically relevant grading scheme for pulmonary squamous cell carcinoma Wilko Weichert, Claudia Kossakowski, Alexander Harms, Peter Schirmacher, Thomas Muley, Hendrik Dienemann and Arne Warth

947 Small cell lung cancer in never-smokers

María Torres-Durán, Alberto Ruano-Ravina, Karl T. Kelsey, Isaura Parente-Lamelas, Mariano Provencio, Virginia Leiro-Fernández, José Abal-Arca, Carmen Montero-Martínez, Iria Vidal-Garcia, Carolina Pena, Olalla Castro-Añón, Antonio Golpe-Gómez,

Cristina Martínez, Rosirys Guzmán-Taveras, María José Mejuto-Martí, Alberto Fernández-Villar and Juan Miguel Barros-Dios

Mechanisms of lung disease

954 Influenza virus damages the alveolar barrier by disrupting epithelial cell tight junctions

Kirsty R. Short, Jennifer Kasper, Stijn van der Aa, Arno C. Andeweg, Fatiha Zaaraoui-Boutahar, Marco Goeijenbier,

Mathilde Richard, Susanne Herold, Christin Becker, Dana P. Scott, Ronald W.A.L. Limpens, Abraham J. Koster,

Montserrat Bárcena, Ron A.M. Fouchier, Charles James Kirkpatrick and Thijs Kuiken

\section{BACK TO BASICS}

967 The emerging role of myeloid-derived suppressor cells in lung diseases

Saeed Kolahian, Hasan Halit Öz, Benyuan Zhou, Christoph M. Griessinger, Nikolaus Rieber and Dominik Hartl 
Research letters

Sputum inflammatory cells in COPD patients classified according to GOLD 2011 guidelines

Maria Laura Bartoli, Francesco Costa, Laura Malagrinò, Dario Nieri, Sandra Antonelli, Giovanna Decusatis, Claudia De Simone, Sabrina Santerini, Silvana Cianchetti, Manuela Latorre, Barbara Vagaggini and Pierluigi Paggiaro

981 Description of randomised controlled trial of inhaled corticosteroid/fast-onset LABA reliever therapy in mild asthma Richard Beasley, lan Pavord, Alberto Papi, Helen K. Reddel, Tim Harrison, Guy B. Marks, Robert J. Hancox and Mark Weatherall

985 Asthma and respiratory allergy prevalence is still increasing among Finnish young adults Pekka Jousilahti, Tari Haahtela, Tiina Laatikainen, Mika Mäkelä and Erkki Vartiainen

987 Obstructive sleep apnoea as a risk factor for osteopenia and osteoporosis in the male population

Claudio Liguori, Nicola Biagio Mercuri, Francesca Izzi, Andrea Romigi, Alberto Cordella, Eleonora Piccirilli, Salvatore Viola, Silvio Costa, Paolo Sbraccia, Maria Grazia Marciani, Umberto Tarantino and Fabio Placidi

990 Deficient interleukin-17 production in response to Mycobacterium abscessus in cystic fibrosis

Katharina L. Becker, Jakko van Ingen, Jaap ten Oever, Peter J. Merkus, Gerben Ferwerda, Mihai G. Netea, Cecile Magis-Escurra, Monique H. Reijers and Frank L. van de Veerdonk

994 Does mass spectrometric breath analysis detect Pseudomonas aeruginosa in cystic fibrosis? Rishi Pabary, Juzheng Huang, Sacheen Kumar, Eric W.F.W. Alton, Andrew Bush, George B. Hanna and Jane C. Davies

997 Monoallelic germline ATM mutation and organising pneumonia induced by radiation therapy to the breast Jean-François Cordier, Vincent Cottin, Romain Lazor and Dominique Stoppa-Lyonnet

1000 Regimens for nontuberculous mycobacterial lung disease lack early bactericidal activity Michiel H.C. Slaats, Wouter Hoefsloot, Cecile Magis-Escurra, Martin J. Boeree, Melanie Wattenberg, Saskia Kuipers and Jakko van Ingen

1003 Low paediatric tuberculosis case detection rate in Southern Mozambique

Elisa López-Varela, Orvalho Joaquim Augusto, Luis Guerra, Durval Respeito, Charfudin Sacoor, Jahit Sacarlal, Giovanni Battista Migliori, Giovanni Sotgiu, Pedro L. Alonso and Alberto L. García-Basteiro

1005 Polymers of $Z \alpha_{1}$-antitrypsin are secreted in cell models of disease

Annamaria Fra, Francesca Cosmi, Adriana Ordoñez, Romina Berardelli, Juan Perez, Noemi A. Guadagno, Luciano Corda, Stefan J. Marciniak, David A. Lomas and Elena Miranda

Correspondence

1010 Practical tools for implementing early palliative care in advanced lung cancer Annelies Janssens, Liesbeth Teugels, Sisca Kohl, Toke Michielsen, Bert Leysen and Jan P. van Meerbeeck

1012 Paradoxical decrease in isoprostane and increase in superoxide dismutase following CPAP withdrawal in OSA Denis Monneret and Dominique Bonnefont-Rousselot; Charalambos Antoniades, Regent Lee, Malcolm Kohler and John Stradling 